Their surface was marked with ridses (6), and they had a central hollow divided by diaphragms."

I will examine these statements seriatim.

(I) The author appears to have been strangely ignorant of Sir William Dawson's magnificent discoveries of Calamites and other Carboniferous plants in the Devonian strata of North America, announced in his Report on the subject in $187 \mathrm{I}$.

(2) In 1874 I published in the Philosophical Transactions the detailed structure of extremely beautiful examples of Calamostachys Binneyana, and, since then, Prof. Weiss, of Berlin, has figured equally fine examples of Calamostachys Ludzigi. In the Philosophical Transactions for 188 I I further showed that this genus comprehended both homosporous and heterosporous forms. At the same time Calamostachys is not the fruit of Calamites.

(4) Both Sir William Dawson and Prof. Weiss have shown that the slender twigs of Calamites were abundantly supplied with verticils of linear leaves.

(5) This statement is true with an important limitation, which Dr. Goebel ignores; or, as a follower of M. Renault, he more probably rejects. Whilst the type of Calamitean organisation is unquestionably Equisetiform, their arborescent stems and branches contained an enormous xylem or woody cylinder, developed exogenously, which made them differ very widely from their degenerate living representatives.

(6) This is a repetition of the old fallacy, which regarded the vertical groovings of the surfaces of the inorganic casts of the fistular medullary cavity as belonging to the cortical surface. We have now numerous sections of the Calamitean cortex, no one of which exhibits the slightest trace of vertical flutings; they are all smooth.

On p. 281, speaking of heterosporous Lycopodiacea, the author accepts M. Renault's old conclusions that in Lepidodendron "there is no certain indication of secondary growth in thickness." "The connection of fossil stems capable of great increase in thickness, such as the Sigillarieæ and Calamodendron is at present questioned." These facts are no longer capable of being justly questioned. The structure of Lepidodendron Selaginoides alone suffices to settle the matter so far as that genus is concerned; to say nothing of the many other species that demonstrate the same fact. M. Grand'Eury himself, long one of the most influential questioners, has now recognised that the genus Arthropitus only represents the thick woody zone of a true Calamite. Prof. Stur, of Vienna, long ago demonstrated in an unanswerable manner the almost absolute identity of Calamites and Calamodendron ; and M..Renault himself, as I have already observed, has still more recently been compelled by the discovery of a Sigillarian fructification by M. Zeiller to alter his view respecting the Sigillariæ. He no longer insists that these cannot be Ciyptogams because their stems grow exogenously, but now hands over to his opponents, who have so long contended for the Lycopodiaceous affinities of this Sigillarian genus, all the vertically fluted examples of it.

Whilst deeming it desirable that his readers should be put in possession of the other side of the question to which he refers, it is only fair to Dr. Goebel to say he is himself aware that those questions are dealt with in a one-sided manner. In a footnote on p. 272 of the English translation the author says :- "The short description given in the text from Renault may serve at least to draw attention to these interesting types, in which there is much that is yet uncertain. We cannot enter here into disputed or doubtful points." At the same time it is to be lamented that the leading botanists of the world cannot give us palæontologists more of that valuable aid which their special studies would so well enable them to do. I do not yet despair of enlisting some of the Strasburgers, de Barys, Goebels, and Van Tieghems in this honourable service.

Owens College

\section{A Sparrow chasing Two Pigeons}

ON Sunday, I asked three men what they were observing, when they pointed out a sparrow chasing two pigeons.

The pigeons were evidently greatly alarmed at their pugnacious attendant, who took occasional pecks at them when flying underneath, and whenever possible. The sparrow lost ground when the others made their more rapid doubling, but soon came up with them again, and renewed its attack.

What was the original quarrel of course we do not know, but the persistency of the sparrow's attack greatly amused us.
Have any of your readers observed anything like this? or is there any record of the like?

Luton, Chatham, March I4

E. A. C.

\section{Top-shaped Hailstones}

I DREW attention to hailstones possessing the above form in Science Gossip of December 1884. These pellets, which fell in my garden at Polmont, Stirlingshire, on the morning of May 6, I884, were about one-fourth of an inch in length, and nearly three-sixteenths of an inch across. I did not see any horizontal stratification as observed by your correspondent Mr. Middlemiss, but found that each transverse section, when examined by a good lens, exhibited a fairly well-marked internal radiated fibrous structure, somewhat similar to that shown in sections of the mineral wavellite. Below are two (transverse

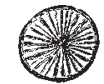

Frg. x.-Transverse section (near base of cone) $\times 2$.

and longitudinal) diagrammatic sections of the Polmont hailstones.

Since then, however, I have found top-shaped hailstones com-
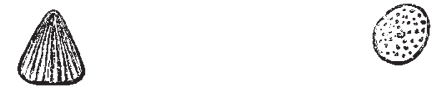

FIG. 3.-Longitudinal section. FIG. 4.-Transverse section of Fig. 3.

posed of fibres radiating from the summit of the pyramid as shown in Fig. 3.

Edinburgh University

\section{A Peculiar Radiation of Light}

AT $10.30 \mathrm{p} . \mathrm{m}$. this evening, my attention was called to a peculiar radiation of light in the eastern sky. The centre of radiation was due east, and the bars on the right-hand side were increased in brilliancy by light evidently arising from the moon, which was not visible, but concealed by cloud. The extent of these rays was from horizon to zenith; the rays being of unequal size, but of a pale gray colour, slightly iridescent.

The east wind was blowing smartly at the time, and I should like to be informed whether this strangely beautiful appearance in the sky was caused by the radiation of light from a rising moon on thin cloud;, or was it the effect of a strong current of wind from a given point?

By i p.m. the moonlight was full; the moon still to the right of the axis of the rays, and the rays nearly dispersed.

Falmouth, March 12

Robert D. Gibney

\section{THE CHEMICAL SOCIETY'S ANNIVERSARY $M E E T I N G$}

THE anniversary meeting of the Chemical Society was held on Wednesday, March 30 . We give some extracts from the address of the President, Dr. Hugo Müller, on the recent progress of chemical science :-

As we contemplate this ceaseless activity in chemical research now manifested all over the world, and which from year to year is continually on the increase, we are nevertheless bound to recognise the fact that vast as the work thus accumulated may appear, there remains still much to be accomplished. The more the field is worked the richer will be the harvest.

Overwhelmed by the quantity of material, especially in the direction of the production of new compounds, hasty critics were wont to denounce such work as superfluous, but it is now generally recognised that we must still continue with the patient and careful elaboration of the substructure of facts before we can with advantage proceed with the longed-for rearing of the edifice of a comprehensive scientific generalisation, that is to say, of ideal chemistry.

The infinite complexity which inquiry reveals in every 